\title{
América Latina: de la independencia de España a la crisis de 1929-30
}

Luis Armando González

CIDAI

Universidad Centroamericana (UCA)

San Salvador

RESUMEN: El presente ensayo esboza, en líneas generales, las características del ciclo bistórico que va de la independencia de España a la crisis de 1929-30 en América Latina.

ABSTRACT: The following essay outlines the main features of the bistorical period that ranges from the independence to the 1929-30 crisis in Latin America.

\section{Introducción}

Octavio Paz lo dijo con contundencia: en Nueva España, un catolicismo ortodoxo -imbuido de la contrarreforma, el espíritu de cruzada y el neotomismo'- preservó a la sociedad colonial de la amenaza del cambio económico, social, político y cultural. Ese catolicismo orientó el quehacer tanto de artistas como de universitarios; de los cortesanos, los sacerdotes $y$ los funcionarios.

"Si la arquitectura es el arte que mejor manifiesta el carácter y las tendencias de una sociedad —dice O. Paz-, Nueva España fue una vasta 
plaza en la que se enfrentaban y confrontaban el palacio, el ayuntamiento y la catedral: el príncipe y su corte, el pueblo en su pluralidad de jerarquías y jurisdicciones; la ortodoxia religiosa. Fuera de la plaza, otras tres construcciones: el convento, la universidad y la fortaleza. El convento y la universidad eran los centros del saber; la fortaleza defendía a la nación del exterior. Pero el convento y la universidad también eran fortalezas: no defendían a la Nueva España de los piratas y de los nómadas sino del tiempo... El enemigo era la historia, esto es, la forma que asumió el tiempo histórico en la Edad Moderna: la crítica. Nueva España no estaba hecha para cambiar sino para durar... Su ideal era la estabilidad y la permanencia; su visión de la perfección era imitar, en la tierra, el orden eterno"2.

Sin embargo, el cambio llegó, no sólo a Nueva España, sino al conjunto de los territorios dominados por España en América. Los movimientos independentistas marcaron los inicios de un proceso de cambio social, económico, político y cultural que permitió a los países recién liberados de la tutela española iniciar, no sin tropiezos, conflictos y equivocaciones, su andadura como naciones independientes. Con la Independencia de España se inicia un ciclo histórico en América Latina que prácticamente se cierra con la crisis de 1929-30, cuando fracasa el modelo económico y político fraguado por las élites oligárquicas una vez que se superaron -al cierre del siglo XIX - la inestabilidad, los caudillismos y los conflictos entre liberales y conservadores de las décadas precedentes.

Estas notas tienen como finalidad esbozar, en sus grandes líneas, el ciclo histórico descrito, es decir, el ciclo histórico que va de la independencia de España a la crisis de 1929-30. Se trata de un esfuerzo de aproximación a la historia latinoamericana, que se complementa con dos trabajados ya publicados: "Las ideas filosóficas de Sor Juana Inés de la Cruz" (Realidad, 98, marzo-abril de 2004, pp. 195-228), en el que -a propósito de la figura de la monja y poeta mexicana, y siguiendo a Octavio Paz-se hace una caracterización de la sociedad y la cultura de Nueva España durante la época colonial-y "Populismo, dictaduras militares y transición-consolidación democrática" (ECA, No. 677-678, marzo-abril de 2005), en el que se reconstruyen, de los años treinta y cuarenta hasta los años noventa del siglo XX, los hitos más relevantes de la historia política latinoamericana.

\section{Los movimientos independentistas}

El orden colonial comenzó a resquebrajarse —dando paso a los 
procesos de independencia - por un conjunto de factores que hubieran podido ser mejor asimilados por una sociedad menos rígida que la sociedad colonial. ¿Cuáles fueron esos factores?

Ante todo, el malestar de los criollos ante lo que consideraban abusos de la corona y sus funcionarios (impuestos, control peninsular del comercio, minusvaloración de su aporte a la empresa colonial, relegación a un puesto de segunda importancia). La mentalidad y resentimiento criollos van a ser claves en la crisis del orden colonial: los criollos se consideran los auténticos dueños de América hispana y con derechos exclusivos para explotar sus recursos y su gente. Los criollos quieren ocupar el lugar político que creen les corresponde, es decir, convertirse en los dirigentes de las sociedades coloniales.

"Los criollos... no tenían en sus manos el gobierno de la provincia. Tampoco poseían todas las fuentes principales de riqueza, ni controlaban a los indigenas en forma absoluta... Aquella clase compartía el poder económico y político, en un plano de subordinación, con la monarquía española representada en sus funcionarios. Era una clase dominante a medias... Entre los descendientes de los conquistadores y primeros colonos -es decir, entre los criollos- fue desarrollándose un sentimiento de suficiencia y de rebeldía frente al dominio de España, conforme aumentaba la capacidad productiva de sus propiedades y se hacían económicamente más fuertes. La culminación de este proceso fue la Independencia, pero el proceso mismo se observa a lo largo de los tres siglos coloniales: un forcejeo constante entre los funcionarios reales y los criollos como clase social"'s.

En segundo lugar, las ideas ilustradas, que comienzan a llegar a tierras americanas a finales del siglo XVIII y que son asumidas y defendidas por los intelectuales criollos. Esas ideas -que se difunden a través de panfletos, por viajeros y comerciantes- hablan del derecho a la autodeterminación de los pueblos, de libertad, fraternidad e igualdad, de la emancipación por el conocimiento y la razón, del rechazo a la autoridad civil y religiosa, y de la importancia de la ciencia para organizar la vida los pueblos. Los intelectuales criollos más críticos se convierten defensores de esas ideas, escriben en periódicos, hacen reuniones secretas, discuten a viva voz sobre ellas y las usan para oponerse a la corona y a sus funcionarios en tierras americanas. Se comienzan a perfilar las "ideologías de la independencia", influidas tanto por el liberalismo político como por el liberalismo económico4. 
Temas como los derechos de expresión y asociación, el libre debate de ideas, la elección y revocación de mandatos comienzan a ser parte de las discusiones de los criollos. Rousseau, Montesquieu y Locke -entre otros autores - comienzan a ser citados como parte de los argumentos en defensa de los derechos políticos de los criollos. A ello se suma el impacto de la independencia de Estados Unidos (1776), con su proclamación de los derechos civiles y políticos para sus habitantes, y, poco después, la revolución francesa (1789), con sus ideales de libertad, igualdad y fraternidad. El periódico El Editor Constitucional - fundado en 1820va a asumir con vehemencia, como una de sus banderas de lucha, la defensa de las libertades políticas de los ciudadanos. "En el pueblo en donde no se pueda señalar con el dedo el acto de arbitrariedad del magistrado — se dice en el número 12 de febrero de 1821—; el prevaricato del funcionario público; la vergonzosa fragilidad de un empleado; el abandono que un Representante hizo de sus constituyentes; alli no hay libertad y los derechos del hombre están obstruidos. Este es un pueblo que he llagado perder los sentimientos primitivos de la libertad: es una asociación de esclavos estúpidos y miserables, o un rebaño de bestias condenadas al trabajo, y a no salir de la senda ni del paso a que las obliga la mano imperiosa del conductor"s.

También se escuchan voces que hablan del libre comercio, de la libertad de empresa, del trabajo productivo, de las empresas industriales y de la necesidad de abrirse al comercio con otras regiones del mundo. De nuevo, el El Editor Constitucional hace eco, con un claro trasfondo empiristas y sensualistas, de las nuevas ideas productivistas. "El hombre es activo por naturaleza - se lee en sus páginas-, como que está dotado de una máquina admirable y de una inteligencia que da infinitos usos a esta misma máquina. No hay animal que iguale al hombre en la organización de la mano, cuya estructura es acomodada para ejecutar mil diversos movimientos, simples y combinados de muchos modos diferentes. Reside en ella, particularmente, el sentido del tacto, y esta ocurrencia del sentido del movimiento la hace el instrumento más apto para conocer y ejecutar... ¿Cómo haremos para dirigirlo [al hombre] de modo que no sólo emplee el vigor de sus brazos en trabajos útiles, sino que también desarrollo en ellos su talento? Es necesario que el hombre sepa hacer uso de su entendimiento, y que no sea un estúpido patán del campo; es menester que aprenda al mismo tiempo a discurrir y a trabajar con gusto"

Estas ideas económicas y políticas van a ir dando forma mental al proyecto de los criollos en su oposición a la corona española?. Van a ser

Reclidad 105, 2005 
el sueño de los que abanderaron la independencia, es decir, su guía y aspiración. Los periódicos se convierten en el foco de propagación de esas ideas; se trata de un periodismo de combate, polémico y mordaz. Por ejemplo, en Centroamérica El Amigo de la Patria (1820) se convierte en defensor del libre comercio, mientras que La Gaceta de Guatemala (1797) aborda temas de economía política. Y El Editor constitucional - del cual ya hemos tomado un par de citas - desarrolla temas como la democracia y las libertades civiles, aunque si dejar de abordar asuntos económicos, incluido el problema de libre comercio ${ }^{8}$.

Se asiste aquí a los primeros brotes de una opinión pública, es decir, de un posicionamiento ciudadano —el de los intelectuales - que va siendo compartido por distintos grupos sociales acerca de los problemas que son competencia de la mayoría. Con el influjo de los periódicos, la cultura de la palabra hablada ya no está sola, aunque seguirá siendo dominante durante mucho tiempo. De hecho, terminarán mezclándose y alimentándose mutuamente. $O$ incluso la retórica verbal se plasmará en los textos escritos casi mecánicamente. Se tendrá una abundancia en la escritura, proclive al barroquismo y al circunloquio.

En tercer lugar, la crisis política en España, cuando Napoleón obliga a abdicar al rey Fernando VII (1808) y pone a José Bonaparte en el trono. Esta situación en España deja a América sin su autoridad suprema, lo cual abre un espacio para que se puedan organizar gobiernos locales - con presencia criolla-, que les permiten saborear al poder. Esto se ampara en la Constitución española de 1812 que da pie a los llamados cabildos constitucionales, tanto en España como en América. En México, por ejemplo, "la disidencia y oposición al gobierno virreinal se manifestó con mayor fuerza en la coyuntura presentada por el establecimiento de un sistema constitucional. Al conocer las ventajas que les daba esta estructura de gobierno, los criollos desde el ayuntamiento comenzaron a presionar para que se aplicara con toda precisión... Las elecciones municipales del 29 de noviembre de 1812 pusieron de manifiesto la fuerza alcanzada por los criollos a través del manejo del voto corporativo. La elección 'permitió que los notables criollos conquistaran, no sólo el control sobre el cabildo, que ya detentaban, sino, sobre todo, el espacio urbano'"'.

Al fin y al cabo, los criollos lo pueden hacer por sí solos, sin la presencia molesta de los funcionarios peninsulares. En este momento se hace una segunda división de la región, que dará pie a lo que luego serán sus futuros estados, es decir, se crean las diputaciones provinciales. Con estas

América Lotina: de la independencia de España a la crisls de 1929-30 
últimas se establecen gobiemos propios en cada provincia (la provincia fue una primera división territorial y social de las tierras americanas, adscrita a un Virreinato: México, Perú y Río de la Plata).

Pese a que Fernando VII volvió al poder en 1814 y abolió la Constitución, las cosas no volvieron a ser iguales ni en España y ni en América. Las ideas liberales ya habían hecho mella en los españoles de ambos lados del Atlántico, y las mismas se vieron reforzadas por la experiencia de gobierno constitucional tenida entre 1812 y 1814. Los periódicos hacen lo suyo; en sus páginas se discuten los problemas del momento, se divulgan las nuevas ideas y se ataca a las autoridades. En 1820 se restablece la Constitución de Cádiz y con ello se "dio inicio a una nueva etapa en la vida política de la Nueva España al resurgir con mayor vigor los movimientos autonomistas locales (con los ayuntamientos) y regionales (con las diputaciones provinciales)"'10.

La situación de México - crisis militar y firma del Plan de Iguala (1821) - repercute casi inmediatamente en toda América Latina. Y ello no sólo porque en México está el Virreinato más importante, sino porque es centro de difusión de ideas y porque las posibilidades de cambio en este Virreinato son también las del resto de la América española, por más que Venezuela, Colombia, Perú y Ecuador iniciaron antes sus gestas independencistas. "Los peninsulares — señala Tulio Halperin Donghitenían en México mayor gravitación que en cualquier otra comarca de las antiguas Indias; parecía inconcebible que cualquier cambio político que no incluyera una revolución social afectase seriamente a los dominadores de todo el comercio mexicano. Porque se creían dotados de suficiente fuerza local, también los peninsulares podían encarar una separación política de España. Esta se produjo cuando el vuelco liberal de la política española pareció afectar por una parte la situación de la Iglesia, por otra la intransigencia de la lucha contra la revoluciones hispanoamericanas"11.

Por lo general, la proclamación de la independencia consistió en un relevo de poder relativamente pacífico o con apoyo popular marginal. De hecho, México fue la gran excepción por la importancia del Virreinato y por la integración de grupos indígenas-campesinos a los bandos enfrentados ${ }^{12}$. En México, la etapa anárquica comenzó justamente en el marco del proceso independentista: caudillos, guerras civiles, divisiones territoriales y ambiciones de poder se hicieron sentir en la época. No es que todos los que se embarcaron en el movimiento por la independencia estuvieran volcados hacia los sectores populares o buscaran reivindicar 
los derechos campesinos-indígenas, sino que, salvo notables excepciones, los criollos usaron a esos grupos sociales para sus propios fines. No es casual que el Plan de: Iguala, fruto del pacto entre Agustín Iturbide y Vicente Guerrero, consagrara las tres garantías siguientes: Independencia, unidad en la fe católica e igualdad para los peninsulares respecto de los criollos, y preveía la creación de un gobierno designado por Fernando VII ${ }^{13}$. Así pues, en México, "la separación política de la Metrópoli se realiza en contra de las clases que habían luchado por la Independencia. El virreinato de Nueva España se transforma en el Imperio mexicano. Iturbide, el antiguo general realista, se convierte en Agustín I. Al poco tiempo, una rebelión lo derriba. Se inicia una era de pronunciamientos"14.

Esta confluencia de factores hace de los primeros años de 1800 años sumamente conflictivos y de mucha efervescencia en las tierras americanas. Como ya se apuntó, el orden colonial no resiste las presiones, no porque sean excesivamente fuertes, sino por su misma rigidez. De ahí que, cuando esos factores hacen eclosión, el desenlace sea rèlativamente fácil: la corona renuncia a sus posesiones (con poca resistencia de su parte) y los criollos asumen los cargos que habían sido detentados por los burócratas que representaban al rey. Es decir, se produce un reemplazo en el poder: en esencia, en esto consistieron los procesos de independencia, por más que en algunas regiones de América -como Venezuela, Argentina, Colombia o México- los antecedentes que llevaron a ellos hayan sido de mucha violencia ${ }^{15}$.

Los problemas, en realidad, comenzaron después. Los ideales de libertad, igualdad, democracia y los proyectos orientados a crear gobiernos republicanos (y federados), según el modelo estadounidense, no tenían un asidero en la realidad, como bien pronto se dieron cuenta los nuevos gobernantes.

Antes de examinar la situación posterior a la independencia, hay que decir que con ésta no se busca edificar un nuevo orden social, sino que se busca prolongar las instituciones coloniales fundamentales, pese a que muchos de sus protagonistas hubieran insistido en que algo nuevo iba a nacer después de los años veinte del siglo XIX. "La lucha por la Independencia — dice Octavio Paz - tendía a liberar a los 'criollos' de la momificada burocracia peninsular, aunque, en realidad, no se proponía cambiar la estructura social de las colonias. Cierto, los programas y el lenguaje de los caudillos de la Independencia recuerdan al de los revolucionarios de la época. Eran sinceros, sin duda. Aquel lenguaje era

Américo Letina: de la Independencla de Espaio a lo crists de 1929-30 
'moderno', eco de los revolucionarios franceses y, sobre todo, de las ideas de la Independencia norteamericana"16.

La novedad de la situación latinoamericana - traída con la independencia - es, al decir de Paz, "engañosa". "Una vez consumada la Independencia - señala el mexicano- las clases dirigentes se consolidan como las herederas del viejo orden español. Rompen con España pero se muestran incapaces de crear una sociedad moderna. No podía ser de otro modo, ya que los grupos que encabezaron el movimiento de Independencia no constituían nuevas fuerzas sociales, sino la prolongación del sistema feudal. La novedad de las nuevas naciones es engañosa; en verdad se trata de sociedades en decadencia o en forzada inmovilidad, supervivencias y fragmentos de un todo deshecho"17.

En efecto, los movimientos independentistas no logran romper con el legado colonial, sobre todo con el legado de sus instituciones económicas. La matriz misma de los movimientos independentistas debe ubicarse más en "la tradición de las luchas de Cataluña y Portugal contra le hegemonía de Castilla que en la historia de las revoluciones modernas"18. En virtud de ello, la independencia no buscó tanto la fundación de un nuevo orden social y económico - algo propio de las revoluciones modernas- como la negación de España. Aunque es cierto que el propósito era reemplazar "el régimen monárquico español, absolutista y católico, por uno republicano, democrático y liberal"19.

En la misma línea, las ideas liberales y democráticas no se corresponden con la realidad, puesto que no hay una burguesía que las sostenga, aunque los criollos se vean a sí mismos como los nuevos burgueses. Aparece, así, lo que Octavio Paz llama la mentira política como algo constitutivo del ejercicio del poder en América Latina: hacer promesas a partir de unos ideales que son traicionados en la práctica. Los ideales que inspiraron ese propósito fueron los ideales democrático-liberales, tomados de la Revolución de Independencia de los Estados Unidos y de la Revolución francesa. En el primer caso, "la Revolución de Independencia separó a los Estados Unidos de Inglaterra pero no cambió ni se propuso cambiar su religión, su cultura y los principios que habían fundado a la nación"20. En el segundo caso, "en Francia había una relación orgánica entre las ideas revolucionarias y los hombres y las clases que las encarnaban y trataban de realizarlas... Por más abstractas y aun utópicas que pareciesen, correspondían de alguna manera a los hombres que las habían pensado y a los intereses de las clases que las habían hecho suyas"21. 
Por ambos lados, la situación latinoamericana fue distinta. Ante todo, "la Independencia hispanoamericana fue un movimiento no sólo de separación sino de negación de España"22. A su vez, los ideales liberales y democráticos, abanderados por los caudillos hispanoamericanos, "eran máscaras; los hombres y las clases que gesticulaban detrás de ellas eran herederos directos de la sociedad jerárquica española: hacendados, comerciantes, militares, clérigos, funcionarios. La oligarquía latifundista y mercantil unida a las tres burocracias tradicionales: la del Estado, la del Ejército - y la de la Iglesia. Nuestra Revolución de Independencia no fue sólo una autonegación sino un autoengaño. El verdadero nombre de nuestra democracia es caudillismo y el de nuestro liberalismo es autoritarismo"23.

En suma, los procesos independentistas hispanoamericanos estuvieron atravesados por una contradicción, origen de taras como la mentira política, el fraude y la manipulación ciudadana: el divorcio entre los ideales y la realidad. "Las ideas republicanas y democráticas de los grupos que dirigieron la lucha por la independencia no correspondían a la realidad histórica, a la realidad real, de la América española. En nuestras tierras no existían ni una burguesía ni una clase intelectual que hubiese hecho la crítica de la monarquía absoluta y la Iglesia. Las clases que realizaron la independencia no podían implantar las ideas democráticas y liberales porque no había ningún lazo orgánico entre ellas y esas ideas"24. Se rompió con España, pero lo español perduró. Tal como lo dijo Andrés Bello (1781-1865), "arrancamos el cetro al monarca, pero no al espíritu español: nuestros congresos obedecieron, sin sentirlo, a aspiraciones góticas... hasta nuestros guerreros adheridos a un fuero especial, que está en pugna con el principio de la igualdad ante la ley, revelan el dominio de las ideas de esa misma España cuyas banderas hollaron".

La realidad de Hispanoamérica exigía de los líderes de la independencia una dosis de creatividad política que permitiera reelaborar y recrear los ideales liberales y democráticos. En lugar de ello, "prefirieron apropiarse de la filosofía política de los franceses, de los ingleses y de los norteamericanos. Era natural que los hispanoamericanos procuraran hacer suyas esas ideas y que quisieran implantarlas en nuestros países: esas ideas eran las de la modernidad naciente. Pero no bastaba con adoptarlas para ser modernos: había que adaptarlas. La ideología republicana y democrática liberal fue una superposición histórica. No cambió a nuestras sociedades pero sí deformó las conciencias: introdujo la mala fe y la mentira en la vida política"rs. 
Por último, el derrumbe del imperio español no sólo trajo la división territorial por obra de las oligarquías nativas, sino la influencia determinante, de aquí en adelante en la historia latinoamericana, de los caudillos: figuras carismáticas que van a intentar asumir por su cuenta y riesgo la conducción autoritaria de sus respectivas naciones. "La imagen del 'dictador hispanoamericano' - dice Paz- aparece ya, en embrión, en la del libertador"26.

2. De la independencia al primer cuarto del siglo XX: la etapa de la anarquía y los regímenes oligárquicos

Al siguiente día de la independencia, la contradicción entre ideales y realidad estalla violentamente a favor de la realidad. La fragmentación territorial, social y económica, así como las ambiciones de los caudillos locales, hacen que la región latinoamericana se sumerja en un caos, prácticamente desde 1840 hasta 1870 y quizás un poco mas adelante. Esta es la etapa conocida como la de la anarquía, en la cual se desatan sangrientas guerras civiles encabezadas por caudillos militares que se adscriben ya sea al bando liberal o al bando conservador. Los liberales, por lo general, van a ser anticlericales, integracionistas y partidarios de una reforma económica que abra a la región a los mercados internacionales.

Los conservadores van a apostarle a lo contrario: van a ser proeclesiásticos, defensores de las autonomías nacionales y partidarios de los vínculos económicos tradicionales con España. Entre unos y otros se intercalan los intereses de poder, las ambiciones personales, las componendas y los arreglos, así como el tránsito de una adscripción a otra con relativa facilidad. La etapa anárquica deja atraso económico, una población diezmada por las enfermedades, el hambre y la guerra, desolación y desorden.

Sólo como ejemplos significativos, en Colombia la primera guerra civil estalló en 1813; desde este año hasta principios de 1900 el país tuvo unas treinta guerras civiles y la última de ese periodo - la guerra de los mil días- dejó unos 100 mil muertos, pobreza y enfermedades ${ }^{27}$. En Centroamérica, después de 1821 se produjeron tres guerras federales: 1826-1829; 1831-1833; 1837-1839. Luego vinieron una serie de guerras entre los países y al interior de ellos. Para el caso, en El Salvador, los conservadores y los liberales se reemplazaron en el poder en un promedio de cada 6 años, hasta la llegada de Rafael Zaldívar en $1876^{28}$.

Ciertamente, estas luchas, aunque motivadas por factores internos, no son ajenas al influjo internacional, concretamente de Francia, España e 
Inglaterra ${ }^{29}$, que alientan con sus ambiciones expansionistas los conflictos internos. Como hace notar Halperin Dongui, "no es extraño que en esa primera etapa de afirmación de un orden nuevo abunden las luchas; hay sobradas causas internas para ello. Hay también algunas exteriores: la actitud que lleva a Francia a intervenir en los asuntos latinoamericanos no es sino un aspecto de la reaparición de fuerzas ultramarinas, que no por ser tradicionales dejan de participar en la expansión general de Europa.

Así, junto con Francia aparece España, que con un nivel más modesto está buscando también ella reconciliar sus oposiciones internas en una política activa hacia fuera. Las tentativas españolas... son de consecuencias más limitadas. Pero, en 1845-46, la reaparición del general Flores en el Pacífico meridional, al frente de una expedición organizada desde la ex metrópoli, sirve para enconar una guerra civil en Ecuador y hacer más tenso el clima político desde Chile a América Central. Resultados aun más amplios tiene la desconcertante política de ataques $\mathrm{e}$ incursiones llevadas a cabo en el mismo teatro en $1864-65$ por la flota española de Pareja y Méndez Núñez: si el régimen político chileno, que estaba atravesando una delicada transición, salió indemne del conflicto, en Perú éste contribuyó a provocar un cambio de gobierno"30.

Hacia los años setenta y ochenta, los diferentes bandos -agobiados por las deudas y cansados de tanto guerrear- o son doblegados por sus enemigos o llegan a acuerdos para reorganizar las sociedades, dando lugar a lo que Tulio Halperin Donghi llama el "nuevo pacto colonial". A partir de esos años comienzan a configurarse los Estados oligárquicos -que tendrán vigencia desde los años 70-80 del siglo XIX hasta los años 30 del siglo siguiente-, cuyos límites económicos - aunque también políticos y sociales - serán notorios desde sus mismos inicios. "En 1880 -años más, años menos- el avance en casi toda Hispanoamérica de una economía primaria y exportadora significa la sustitución finalmente consumada del pacto colonial impuesto por las metrópolis ibéricas por uno nuevo. A partir de entonces se va a continuar la marcha por el camino ya decididamente tomado. $\mathrm{El}$ crecimiento será aun más rápido que antes, pero estará acompañado de crisis de intensidad creciente: desde las primeras etapas de su afirmación, el orden neocolonial parece revelar a través de ellas los límites de sus logros"31.

|Con los Estados oligárquicos se logra una relativa estabilidad en las sociedades latinoamericanas. A nivel político, las familias terratenientes logran establecer pactos de gobernabilidad que consisten en turnarse -a

América Lotina: de la independencta de Espoña a la crists de 1929-30 
partir de unas reglas democráticas mínimas - en la gestión estatal. Se establecen cuerpos constitucionales que nominalmente dan pie a gobiernos republicanos, democráticos y representativos, pero que en realidad sólo sirven de fachada a unos sistemas políticos clientelares, en los que fuera de la participación política - por acuerdos entre las familias oligárquicasse decide quiénes son los que van a gobernar. "Bajo la estabilidad asociada a esta estructura de poder, América Latina salió de su aislamiento, estableciendo un comercio regular y sostenido con ultramar cuyas consecuencias se sintieron en los mercados internos y en el desarrollo de la economía, así como en la transformación mental de las élites. Este el grupo político que, además de crear el instrumento para la acción política común, el Estado, comenzó a construir la infraestructura económica que en gran medida ha servido a América Latina en el siglo XX ${ }^{n 32}$.

En el plano económico, las haciendas se convierten en el núcleo de una economías agrarias volcadas hacia el exterior a través de la producción de materias primas: maderas, caucho, pieles, carne, granos, bananos, metales... se convierten en las fuentes de ingreso y enriquecimiento.

Con gran tino, José Medina Echavarría ${ }^{33}$ examinó el papel de la hacienda en el desarrollo de América Latina ${ }^{34}$. Para él, la hacienda simboliza el poder de los grandes terratenientes, que se define en función del número de sus subordinados y trabajadores, así como de la extensión las tierras. Sociológicamente, la hacienda también se define en función de la influencia de los terratenientes en el poder político y en la configuración de las relaciones de autoridad, la estructura familiar y en la formación de un prototipo humano. Políticamente, la hacienda llegó a ser un núcleo de poder, muchas veces con respaldo militar, porque era la base desde donde actuaban diversos caudillos y caciques durante las guerras civiles y después de ellas. Para la familia terrateniente, la hacienda no es una simple propiedad, sino que es el soporte y símbolo de su apellido -en continuidad con la cultura nobiliaria española. Desde la hacienda, el hacendado -el cabeza de familia, el patrón- busca las alianzas familiares, económicas y políticas, que sirven para organizar y canalizar su influencia por vastos territorios y hasta las ciudades.

La hacienda es, a la vez, una unidad económica y política que, con las relaciones clientelares que la sostienen y su capacidad productiva, es un mundo cerrado sobre sí mismo. La hacienda es creadora de un modelo de autoridad, el del patrón, que impregna todas las relaciones sociales. Es un modelo del protector-opresor - paternalista y autoritario, a la vez- 
que se establece a partir de la imagen del señor: magnánimo, pero imponente; religiosamente piadoso, pero incontenible con quienes se le resisten. En la hacienda, pues, se vive una vida señorial, donde la ostentación, las relaciones jerárquicas de autoridad y las relaciones clientelares se amalgaman en una unidad social, económica y política singular.

Como dice Aldo Solari, "para la familia propietaria, la hacienda, más que una simple propiedad, es su soporte y el símbolo de su apellido. Desde la hacienda, el hacendado busca alianzas familiares, económicas y políticas que sirven para 'organizar' vastos territorios y que hasta se extienden hacia las ciudades... La hacienda, entendida como unidad económica y política que sirve de soporte material a una familia y sus clientes [con unas] funciones y papeles que indican derechos y obligaciones dentro del orden social... La hacienda creó un modelo de autoridad, el del patrón, que impregna todas las relaciones sociales. Es a la vez el modelo del protector y del opresor - paternalista y autoritario"35.

En definitiva, la hacienda no sólo es una realidad económica, sino una realidad cultural y política. En la hacienda, el patrón no es sólo el que da trabajo, sino el que protege al campesino, a quien éste le debe sumisión. El patrón es patrono: jefe, guía y protector, pero también autoridad a la que le debe respeto y obediencia. El ejercicio político se caracteriza por el mandato imperativo de quien es dueño de un territorio y de todo de lo que en él se encuentra.

Por su parte, la cultura de la hacienda se difunde a toda la sociedad, siendo reforzada por una religiosidad que llama a la resignación y al respeto, pues las cosas son como Dios quiere que sean. La cultura del padrino, del colono, del caporal, del peón, del caballo, la pistola y las botas, del que alza la voz, del que tiene la propiedad más grande y más rica en siembra y ganado. Es decir, una cultura jerárquica y autoritaria. Y la economía se organiza en torno a la hacienda: puertos, carreteras y ciudades tiene como punto de referencia a las grandes plantaciones hacendatarias, desde donde salen los productos que conectan a América Latina con el mercado mundial. Se trata de una economía "hacia fuera", dependiente de los vaivenes del mercado mundial, es decir, de la demanda de materias primas existente en los centros económicos, que en esos momentos están en expansión.

El declive de la hacienda se inicia, ante todo, cuando las ciudades comienzan a hacer sentir su autonomía -a principios del siglo $\mathrm{XX}$-,

387

América Lotinar. de la Independencia de Espoía a la crists de 1929-30 
pues se van convirtiendo en la sede de la vida administrativa, comercial y cultural latinoamericana con independencia de la hacienda. Pero, en segundo lugar, por el impacto que provoca en la región la reestructuración del sistema económico mundial que va a exigir una modernización de los aparatos productivos agroexportadores no del todo coherente con el esquema de la hacienda.

En efecto, a finales del siglo XIX Inglaterra y Alemania están siendo reemplazados como principales ejes del sistema económico internacional por Estados Unidos, que comienza a tener presencia en las relaciones económicas financieras y comerciales con América Latina, desde ese momento en adelante. Es decir, se está operando una reestructuración en el sistema mundial capitalista en el marco del cual las nuevas naciones latinoamericanas y sus actores van a ocupar su lugar como proveedores de materias primas.

En las primeras dos décadas del siglo XX, América Latina ha adquirido un lugar en ese sistema mundial capitalista, que parece bastante estable y que parece propiciar posibilidades de desarrollo para la región. Puertos, carreteras, ciudades, ingresos tributarios, crecimiento de la burocracia, centros comerciales, una naciente clase media... Todo marcha bien para las familias oligárquicas; pero ese auge tiene unas bases sociales y económicas débiles. Es una economía frágil, pues depende totalmente del exterior; y la sociedad que la sostiene es una sociedad atrasada, pobre e ignorante, que vive en los límites de la sobrevivencia.

La crisis de 1929-30 va a poner de manifiesto estas debilidades estructurales. Ante del estallido de la crisis se suscitan una serie de procesos que van a favorecer el cambio de época que se inicia a partir de 1930. En este cambio, va a jugar un papel crucial la élite intelectual nacionalista (y la nueva clase política ${ }^{36}$ ) formada a principios de siglo en las universidades latinoamericanas, menos volcada culturalmente hacia el exterior -como las oligarquías-y reacia a aceptar los cánones señoriales, las jerarquías sociales y el predominio de la producción agrícola. Por ejemplo, esta élite es la que toma la palabra en el movimiento universitario de Córdoba (1918) en la que se defiende la autonomía universitaria y la libertad de cátedra. La universidad se convierte en centro de la protesta y la crítica antioligárquicas, desde esta fecha en adelante. Aparte del influjo liberal, la universidad latinoamericana siente la influencia del socialismo y el comunismo, aun incipientes en aquella época. 
En segundo lugar, la formación de los Estados latinoamericanos que se consolidan a finales del siglo XIX - también entra en choque con la dinámica de la hacienda, excesivamente particularista y volcada hacia al exterior. Los Estados tienen que conciliar intereses diversos, al paso que tienen que velar por el desarrollo interno de los países. Los oligarcas quieren un Estado subordinado a sus intereses, pero la misma configuración constitucional de aquel genera diferencias entre las nacientes burocracias estatales y los intereses de los hacendados. Se comienza a romper la "transacción" entre liberales y conservadores que estuvo en la base de la formación del Estado independiente y que fue la que dio estabilidad a América Latina desde 1880 hasta inicios del siglo XX.

En tercer lugar, la crisis de 1929-30 sacude el poder económico y político de los hacendados. Después de esos años, salvo en algunas excepciones como los cuatro de los cinco países centroamericanos Guatemala, El Salvador, Honduras y Nicaragua-, las familias oligárquicas verán socavado su poder de una forma extrema. Una de las consecuencias de la crisis - como veremos luego- va a ser que los Estados latinoamericanos se harán más autónomos, es decir, van a tener "una mayor capacidad para tomar decisiones de política en nombre del 'interés general de la nación'. Ello, en ciertas circunstancias, permitió que las políticas de los gobiernos se dirigieran, por primera vez, a satisfacer las necesidades de los sectores urbanos. Tal fue el caso de los gobiernos populistas como el de Vargas en el Brasil, y el de Perón en Argentina"37.

Antes de pasar al examen de la crisis de 1929-30 vamos a resumir las principales características del régimen oligárquico. En primer lugar, es un régimen fundado sobre la fragmentación territorial. En segundo lugar, el ejercicio político está en manos de la élite terrateniente, cuyo poder descansa en las clientelas y en las alianzas familiares. En tercer lugar, hay un incipiente desarrollo democrático: partidos políticos (familiares) y competencia electoral (amañada). En cuarto lugar, son regímenes excluyentes (en lo social, lo económico y lo político) de la mayor parte de la población que es campesina, con componentes indígenas muy arraigados. En quinto lugar, descansan en la hacienda como unidad económica, política, social y cultural. En sexto lugar, los sistemas políticos oligárquicos se sostienen en un ejercicio de poder hereditario, que de padres a hijos, de hermanos a hermanos y de cuñados a cuñados, permite la estabilidad y la reproducción de las relaciones de poder. En séptimo lugar, bajo estos regímenes se configuran las naciones latinoamericanas:

América latina: de la independencia de España a la crisis de 1929-30 
como unidades de territorio, patria, lugar de morada y de pertenencia, y como "comunidad imaginaria e imaginada" (Benedict Anderson) que incluye lo común - raza, clase, idioma y religión-y excluye lo extraño, lo otro, el enemigo ${ }^{38}$. Este último aspecto, va a nutrir durante la mayor parte del siglo XX los valores políticos latinoamericanos -más del lado de la izquierda que de la derecha ${ }^{39}$ - , como veremos en la segunda parte de este trabajo.

\section{La crisis de 1929-30 y su impacto en América Latina}

La crisis de 1929-30 se ha prestado a diversas interpretaciones. Una de las más tradicionales se inscribe en el esquema clásico de la teoría de las crisis según Marx, es decir, que se trato de una crisis de sobreproducción ${ }^{40}$. ¿Qué dice esta teoría? Dice que el modo de producción capitalista se caracteriza por inundar el marcado de mercancías que, obviamente, deben ser consumidas puesto que es así como el capitalista "realiza" su ganancia". $\mathrm{El}$ asunto es que un rasgo propio del capitalismo es que produce más de lo que la sociedad puede consumir, pues la inmensa mayoría de ésta depende de un salario que, básicamente, le permite adquirir lo necesario para vivir. Una etapa de expansión capitalista -es decir de elevados niveles de producción- desemboca en una contracción: no hay donde ubicar las mercancías, hay que destruirlas, hay que cerrar las fábricas, despedir a los trabajadores y suprimir la demanda de recursos para la producción.

Muchos vieron en la crisis del 29-30 una crisis de este tipo, es decir, una crisis clásica del capitalismo que esta vez abarcó a los principales países capitalistas y que tuvo un alcance mundial. "La crisis sigue subsistiendo como crisis general permanente -dijo Paul Mattick en 1933 - y afecta a todos los campos del capitalismo internacional. No desarrolla ninguna nueva coyuntura sino que se expresa en el constante retroceso de la producción y en un aumento contínuo de los desocupados. Ella es, al mismo tiempo, crisis financiera y agraria... Las tendencias imperialistas agudizan la presión sobre el proletariado en vez de atenuarla... esto demuestra que la crisis no puede ser superada en los marcos del capitalismo". ${ }^{42}$

Una segunda interpretación ve la crisis como resultado del comportamiento del oro desde la primera guerra mundial. El esquema es bastante simple: "durante la primera Guerra Mundial la mayor parte de los países beligerantes abandonaron, temporalmente, el patrón oro $\mathbf{y}$ disminuyeron su demanda para que bajase su precio. De aquí que no 
pudiesen comprar tanto en términos de otros artículos y que los precios subiesen en relación con el oro"43. Al perder valor el oro, los precios de otros bienes - medidos por el patrón oro- se incrementaron, lo cual llevó a una disminución en la demanda de esos bienes. El esquema es simple: menos oroàmenos riqueza monetariaàmás dificultades para compraràlos precios de otros bienes suben. Terminada la guerra, hacia 1924, comienzan de nuevo las compras de oro, es decir, la demanda del metal se incrementa. "Por tanto, el oro subió de valor, pudo comprar más en términos de otros artículos y los precios bajaron"44. Al elevarse el precio del oro - al aumentar la demanda-, disminuyen los precios de otros bienes, por ejemplo las materias primas. Fue en este ciclo de incremento del precio del oro que el comercio mundial se vio fuertemente afectado en 1929-30, particularmente los precios de las materias primas que tendieron a la baja, con su subsiguiente impacto en América Latina. Como concluye Harry Barnes, "estos bajos precios fueron un azote para los labradores y manufactureros, muchos de los cuales no lograron vender sus productos o artículos con provecho"45.

La tercera interpretación se acerca más a esta que hemos reseñado, pero insiste en el carácter especulativo-financiero de la crisis de 1929-30. En aquella época - previa al influjo de Keynes, quien propuso la regulación estatal de los mercados- los bancos y las actividades financieras no estaban sujetos a control alguno; por lo tanto, el flujo de capitales podía cambiar drásticamente si sus dueños (los bancos más grandes) así lo decidían, sin que importara mucho la razón (pánico, posibilidades en otras actividades o pura especulación con las tasas de interés). No es casual -dicen quienes apoyan esta interpretación- que la crisis se localizara en la bolsa de valores de Nueva York, siendo una de las primeras crisis debidas a la especulación financiera y la volatilidad de los mercados financieros de la época. Esta lectura se ve reforzada por lo que sucedió después de la crisis: se crearon mecanismos de regulación del flujo de capitales, de forma que se evitaran las salidas masivas de capital, a discreción de los inversionistas.

"El punto de arranque de la gran depresión - dice Esteban Pérez Caldentey- suele situarse en el colapso bursátil de octubre de 1929 en Estados Unidos... Aunque el fenómeno empezó en Estados Unidos se propagó a todo el mundo debido a la estrecha relación económica que había forjado Estados Unidos con los países europeos después de la primera guerra mundial... A raíz de la caía de la bolsa de Nueva York, quebró el mayor banco austríaco, el Creditansalt, causando graves 
problemas en algunos bancos alemanes. Por su parte, el Reino Unido no pudo asistir la fuga de oro que precipitó el abandono del patrón oro en 1931. A medida que la depresión entró en su fase más aguda, varios bancos estadounidenses quebraron. En 1933, 11000 de los 33000 bancos de Estados Unidos se habían declarado en quiebra... La crisis financiera representó un importante colapso en la producción, los flujos comerciales y el empleo"16.

Como quiera que sea, el impacto de la crisis fue sumamente duro para América Latina. En general, el impacto económico fue inmediato, pues los ingresos por las exportaciones disminuyeron drásticamente entre 19291932 y los países no tuvieron la capacidad para saldar deudas pendientes. Esto se tradujo en el cierre de plantaciones y minas, con lo cual los niveles de desempleo se elevaron hasta niveles extremos. "La crisis mundial de los treinta comenzó claramente por una recesión en los países centrales que se agudizó hasta convertirse en depresión profunda. Ella estuvo acompañada por deflación de los mercados interno e internacional y fue seguida por crisis de pagos de los países deudores, en particular latinoamericanos, causadas por el descenso brusco de sus ingresos, producido por la caída de los volúmenes demandados y de los precios de las materias primas. Posteriormente se impuso en ellos la recesión"47.

La miseria golpeó fuertemente a la mayor parte de la población rural y en menor medida a la urbana, específicamente a los comerciantes, artesanos y burócratas que vieron cómo sus salarios eran recortados o perdían poder adquisitivo. Los desórdenes sociales y las protestas no se hicieron esperar; en la mira de quienes protestaban estaban los caporales, los jueces rurales $\mathrm{y}$, por último, los dueños de las haciendas. Un incipiente movimiento socialista, comunista y anarquista intenta hacerse de las riendas del malestar colectivo para orientarlo políticamente, pero ni unos ni otros están listos para una alianza de esa magnitud ${ }^{48}$.

El impacto de la crisis de 1929-30 en América Latina no se mide sólo por el deterioro de las economías latinoamericanas o por la pobreza y las protestas sociales, sino por lo que sucedió después: la reestructuración de los aparatos productivos y de los sistemas políticos. Estos cambios van a extenderse desde México y Costa Rica hasta el Cono Sur, aunque en algunos países, insertos en esta nueva dinámica, los cambios van a ser más significativos que en otros —así, en Argentina, Chile, México y Uruguay va a ser más clara la tendencia a la superación del régimen oligárquico, mientras que en Brasil, Bolivia y Perú esa dinámica es menos 
nítida9 - dependiendo de sus tradiciones políticas, de sus recursos económicos y de sus élites. Por su parte, Centroamérica, salvo Costa Rica, se distanciará del resto de la región desde los años 30 en adelante: las familias oligárquicas, en alianza con los militares y la iglesia, le van a apostar al poder sobre la tierra y a la producción agrícola para la exportación (llámesele café, algodón, caña de azúcar, banano, madera o carne) como eje de la organización económica, social y política ${ }^{50}$.

Sólo como ejemplo, se puede traer a cuenta el caso argentino, en el cual se suscitaron fenómenos semejantes a los sucedidos en otros países latinoamericanos. Desde 1912, con la introducción del sufragio universal secreto, Argentina había vivido un creciente desarrollo democrático. Sin embargo, como señala Jorge Castañeda, "la presión de la derecha, el desencanto de las clases medias y los estragos causados por la Gran Depresión pusieron término al fugaz lapso democrático: en 1930 el Ejército consuma el primer golpe de Estado del siglo que destituye a un gobiemo latinoamericano democráticamente electo. En su lugar, las fuerzas armadas colocarán al general Félix Uriburu; después del fracaso de su proyecto filofascista, se sucederán gobiernos fraudulentos, hasta que en 1943 el ciclo se cerrará con un nuevo golpe de Estado. La alternancia de gobiernos civiles y militares caracterizará la vida política argentina hasta 1983"s!.

La mayor parte de países —con militares o sin ellos-, después de sortear los momentos más agudos de la crisis, van a iniciar reformas económicas y políticas de gran envergadura. Económicamente, a partir de 1930, se inician los procesos de industrialización sustitutiva de importaciones (ISI), con el objeto de superar la dependencia en la importación de bienes industriales. De lo que se trata es de producir localmente aquellos bienes industriales que se importan y que gravan a las economías nacionales, lo que se percibe - aunque no se teoriza-como un deterioro en los términos de intercambio. Es decir, los bienes industriales cuestan más caro que lo que se obtiene por la venta de materias primas. Asimismo, las élites latinoamericanas caen en la cuenta de que el desarrollo pasa por la industrialización, tal como lo reflejan los Estados Unidos y Europa. Este cambio económico no puede ser realizado sin la participación del Éstado ${ }^{\mathbf{5 2}}$, para lo cual es necesario desplazar del poder a las familias oligárquicas y establecer un nuevo esquema de ejercicio político.

Salvo en Guatemala, El Salvador, Honduras y Nicaragua, en el resto de países latinoamericanos llegan al poder líderes militares o civiles que comienzan a introducir modificaciones en el sistema político 
latinoamericano. Una de las novedades es que los nuevos administradores estatales pretenden poner al Estado por encima de las disputas tradicionales. En segundo lugar, el Estado va a ir asumiendo tareas económicas importantes, en orden a permitir el desarrollo industrial. En estos momentos - años 30 y 40-, en Europa está cobrando auge el Estado de bienestar y esos ecos llegan hasta América Latina. En tercer lugar, las clases medias organizadas comienzan a convertirse en el soporte fundamental de los nuevos liderazgos políticos, surgidos en su mayoría de los sectores medios. Hacia los años 40 , grandes agrupaciones políticas de las clases medias harán sentir su presencia en América Latina. Entre las más importantes van a estar la Alianza Popular Revolucionaria Americana (APRA), del Perú, al Partido Revolucionario Institucional (PRI), de México, el Movimiento Nacional Revolucionario (MNR), de Bolivia, y el Partido Peronista, de Argentina. Así, en la década de los años 40, adquiere su perfil característico lo que se conocerá como el populismo latinoamericano (o los regímenes populistas).

\section{Reflexion final}

Situémonos en la etapa anárquica, sobre todo a su cierre (1870-80) a través de los pactos entre liberales y conservadores. Mediante estos pactos, bajo la fachada de unas reformas o "revoluciones" liberales, se implementan procesos de expropiación de las tierras que, desde la época colonial, estaban en manos de las comunidades indígenas, es decir, de las tierras comunales y ejidales —estas últimas colindantes a las propiedades comunales y destinadas al uso de sus miembros. Estas expropiaciones-que fueron por lo general violentas y con engaños de todo tipo- contribuyen al fortalecimiento de las haciendas tanto en tierras (las mejores pasan a manos de los hacendados) como en mano de obra (los indígenas son forzados a convertirse en campesinos).

En segundo lugar, hay que destacar el papel de la Iglesia (católica) en la etapa oligárquica. Mediante la alianza que estableció con los hacendados y militares la Iglesia pudo conservar, en general, sus privilegios: influencia política y propiedades. Este poder de la Iglesia (y su sesgo conservador) se extiende más allá de la segunda mitad del siglo XX, hasta que el Concilio Vaticano II (1963-1965) ${ }^{53}$ obliga a revisar el rol eclesial tradicional en América Latina, concretamente en las reuniones del episcopado latinoamericano en Medellín y Puebla (1968 y 1978, respectivamente) ${ }^{54}$. Culturalmente, el influjo de la Iglesia católica hasta antes de Medellín y Puebla fue extremadamente conservador. La Iglesia defendió la sumisión 
campesina como norma de conducta, al tiempo que trabajó porque las relaciones de autoridad surgidas en la hacienda se difundieran al conjunto de la sociedad ${ }^{55}$.

Por ejemplo, las relaciones de compadrazgo (y padrinazgo) nacidas en la hacienda se convirtieron en elemento configurador de las relaciones de poder político, así como en mecanismo para su reproducción. Pero el compadrazgo no tenía un significado puramente secular, sino que su significado era religioso. El vínculo entre ahijados y padrinos, y entre compadres, estaba sancionado por la Iglesia, por lo que se trataba de un vínculo que no se podía romper a menos que se renunciara a la legitimidad religiosa ${ }^{56}$.

Por último, a la par del punto anterior, está el tema de los vínculos familiares $^{57}$ en la política oligárquica. Demás está decir que éste no es un invento latinoamericano, sino Europeo o incluso oriental. Es decir, es un invento antiguo. Lo llamativo es que las redes familiares (de poder) que se establecen en la época oligárquica buscan incluir a los potenciales rivales políticos - a modo de crear un círculo amplio para el ejercicio del poder-, de forma que las diferencias políticas e ideológicas se diluyen en los pactos familiares dejando a la sociedad huérfana de opciones.

Esta práctica de buscar alianzas por la vía del matrimonio, el compadrazgo o la amistad con los enemigos políticos se mantuvo en América Latina cuando en Europa y Estados Unidos las redes familiares en la política prácticamente se limitaban al mismo linaje familiar e incluían a quienes profesaban la misma filiación ideológica. Como dicen Diana Balmori, Stuart F. Voss y Miles Wortman, "el proceso de formar redes [familiares] empezó a mediados del siglo XVIII, se expandió durante el periodo de la independencia, se hizo visible en el siglo XIX y llegó a su cúspide a fines de ese mismo siglo... $\mathrm{El}$ poder de las redes se extendió hasta principios del siglo XX, aunque la familia perdió algo de su autoridad política y económica y todo su poder sobre la economía nacional. A lo largo de este siglo, las familias han tenido acceso al poder político y económico en virtud de sus grande fortunas, sus propiedades y sus apellidos. Hasta el día de hoy promueven a ciertos miembros de la familia a posiciones de poder" 58 . 


\section{NOTAS}

1 “El neotomismo - dice Paz- considera a la sociedad como un sistema jerárquico en el cual cada persona y cada grupo sirven un propósito de orden general y universal que los trascienden. Paz, O., Sor Juana Inés de la Cruz o las trampas de la fe. México, FCE, 1983. .., p. 49

2 Ibíd., p. 66

3 Martínez Peláez, S., La patria del criollo, San Jose, EDUCA, 1979, PP. 36-37

4 Cfr. Rodríguez B., V., Ideologías de la independencia. San José, Costa Rica, EDUCA, 1971

$5 \quad$ En Rodríguez B., V., Ideologías de la independencia..., p. 35-36

- En Rodríguez B., V., Ideologias de la independencia..., pp. 49-50

7 Para el caso de Centroamérica, Cfr. Bonilla Bonilla, A., Ideas económicas en la Centroamérica ilustrada. San Salvador, FLACSO, 1999.

- Cfr., Rodríguez B., V., Ideologías de la independencia..., PP 77 y ss.

- Ortiz Escamilla, J., "La ciudad amenazada, el control social y la autocrítica del poder. La guerra civil de 1810-1821". Relaciones, No. 84, otoño 200, p. 41

10 Ortiz Escamilla, J., "La ciudad amenazada, el control social y la autocrítica del poder. La guerra civil de 1810-1821"..., p. 53.

1 Halperin Dongui, T., Historia contemporánea de América Latina. México, Alianza, 1989, p. 138.

12 Cfr. Serrano Ortega, J. A., "Los estados armados: milicias cívicas y sistema federal en México (1824-1835)". En La guerra y la paz. Tradiciones y contradiciones de nuestra cultura. XXII Coloquio de Antropología e Historia Regionales, El Colegio de Michoacán, 2000, Pp. 97-108

13 Cfr., Halperin Dongui, T., Historia contempordnea de América Latina..., Pp. 134 y ss.

14 Paz, O., El laberinto de la soledad. México,, FCE, 1999, p. 135

is Cfr. El análisis que hace Halperin Dongui,, en Historia contemporánea de América Latina, PP. 125 y ss, de la campaña militar de Simón Bolívar

16 Paz. O., El laberinto de la soledad..., p. 132.

17 Paz, O., El laberinto de la soledad..., p. 132.

18 Paz, O., Sor Juana Inée..., p. 29

19 O. Paz, "Literatura y crítica". En Fundación y disidencia. Dominio bispdnico. Obras completas (III). México, FCE, 1994., p. 63

20 Ibíd.

21 Ibíd.

22 Ibid. 
Ibíd., p. 64

O. Paz, Sor Juana Inés de la Cruz o las trampas de la fe..., p. 29

Ibíd., pp. 29-30

Paz, O., El laberinto de la soledad..., p. 133

Cfr., Vargas Llosa, M., García Márquez: historia de un deicidio. Caracas, Monte Avila, 1971, pp. 25-26

Cfr., "La época republicana". En VVAA, Enciclopedia El Salvador (Vol. II). Barcelona, Océano, 1999, pp. 251-266

Para el caso de la influencia inglesa en Centroamérica, Cfr., Naylor, R. A., Influencia britdnica en el comercio centroamericano durante las primeras décadas de la Independencia (1821-1951). Guatemala, Centro de Investigaciones Regionales de Mesoamérica, 1988

Halperin Donghi, T., Historia contemporánea de América Latina..., Pp. 248-249

Halperin Donghi, T., Historia contempordnea de América Latina..., p. 309

Solari, A., "José Medina Echavarría: el hombre y su obra", p. 37

Cfr., Maestre Alfonso, J., José Medina Echaverria. Madrid, Ediciones de Cultura Hispánica, 1991

Cfr., Solari, A., “José Medina Echavarría: el hombre y su obra". En Solari, A. (Comp.), Poder y desarrollo en América Latina. Estudios sociologicos en bomenaje a José Medina Echavarría. México, FCE, 1977, pp. 7-47.

Solari, A., 'José Medina Echavarría: el hombre y su obra”, p. 35

Cfr., Solari, A., "José Medina Echavarría: el hombre y su obra”, pp. 37-38

Silva Michelena, J. A., "Modos de subdesarrollo y relaciones internacionales". En Solari, A. (Comp.), Poder y desarrollo en América Latina..., p. 249

- Cfr., González, L. A., “El nacionalismo latinoamericano en los umbrales del siglo XXI”. ECA, No, 555-556, enero-febrero de 1995, PP. 112-116.

- Cfr., Castañeda, J. C., La utopia desarmada. Intrigas, dilemas y promesas de la izquierda en América Latina. México, Joaquín Mortiz, 1993

Cfr., Mattick, P., "La crisis mortal del capitalismo". En AAVV, ¿Dertumbe del capitalismo o sujeto revolucionario? México, Pasado y Presente, 1978, pp. 132-147; Mattick, P., Marx y Keynes. México, ERA, 1985, capítulo 9: "El capitalismo en crisis"; Grossmann, H., La ley de la acumulación y el desarrollo del capitalismo. México, Siglo XXI, 1978; Grossmann, H., Ensayos sobre la teoria de la crisis. México, Pasado y Presente, 1978.

4 Cfr., Sweezy, P., Teoría del desarrollo capitalista. México, FCE, 1984

Mattick, P., "La crisis mortal del capitalismo", p. 139

Bames, H. E., Historia de la economía del mundo occidental. México, UTEHA, 1967, p. 812 
Barnes, H. E., Historia económica del mundo occidental..., p. 813

Barnes, H. E., Historia económica del mundo occidental..., p. 813

Pérez Caldentey, E. "Milton Friedman". Comercio Exterior, No. 1, enero de 2001, Pp. 26-27

Puchet Anyul, M., "La coyuntura actual y la crisis de los treinta en América Latina". En AAVV, El impacto político de la crisis del 29 en América Latina. México, Alianza Editorial Mexicana, 1989, p. 166

El caso de El Salvador es aleccionador en este sentido: el ritmo de la protesta campesina en 1932 fue distinto del ritmo que quiso imprimirle el Partido Comunista. Este quería orientar a los campesinos - vistos como proletarios- hacia la revolución en un esquema de los sóviets, mientras que aquellos buscaban vengarse de los malos tratos de los caporales y los jueces rurales. Asimismo, su desesperación tenía un fuerte condicionamiento económico y social, lo cual daba poco espacio a la ideología y los objetivos políticos. Cfr., Anderson, Th., El Salvador, 1932. Los sucesos políticos. San Salvador, CONCULTURA, 2001. En este mismo volumen se encuentran dos trabajos también interesantes y de lectura obligada: Pérez, Brignoli, H., "La rebelión campesina de 1932 en El Salvador" (pp. 17-54) y Ching, E., "Los archivos de Moscú. Una nueva apreciación de la insurrección del 32" (pp. 55-63).

Cfr., AAVV, El impacto político de la crisis del 29 en América Latina..., Pp. 9 y ss.

Cfr., Cardenal, R, Manual de historia de Centroamérica. San Salvador, UCA editores, 1998

Castañeda, J., La vida en Rojo. Una biografía del Che Guevara. México, Alfaguara, 1997, p.28.

Cfr., González, L. A., "Estado, mercado y sociedad civil en América Latina". ECA, No. 552, octubre de 1994, PP. 1045-1056.

Cfr. Documentos completos del Vaticano II. Bilbao, El Mensajero, 1986.

Cfr., Los Obispos latinoamericanos entre Medellin y Puebla. Documentos Episcopales. San Salvador, UCA editores, 1978.

Para el caso de El Salvador, Cfr., Cardenal, R., El poder eclesiástico en El Salvador. San Salvador, CONCULTURA, 2000

Para el caso de El Salvador, Cfr., Montes, S., El compadrazgo, una estructura de poder en El Salvador. San Salvador, UCA editores, 1979

Cfr. Balmori, D., Voss, S. F., Wortman, S., Las alianzas familiares y la formación del país en América Latina. México, FCE, 1990; Guerra, F. X., México: del Antiguo Régimen a la revolución. México, FCE, 1991 (2 Vol.).

Balmori, D., Voss, S. F., Wortman, S., Las alianzas familiares y la formación del país en América Latina..., Pp. 26-27. 